\title{
Discussion on the Coordination of Aesthetics and Ergonomics Based on the Self-express in Product Design
}

\author{
Jiao-Jiao WANG ${ }^{1, a,{ }^{*}}$, Can-Qun $\mathrm{HE}^{2, \mathrm{~b}}$, Wen-Jing $\mathrm{XU}^{3, \mathrm{c}}$ \\ ${ }^{1}$ Art school of Jiangsu University, Zhenjiang, Jiangsu, China 212013 \\ ${ }^{2}$ College of Mechanical Electrical Engineering of Hohai Institute , Changzhou, Jiangsu, China 213000 \\ ${ }^{3}$ Art school of Jiangsu University, Zhenjiang, Jiangsu, China 212013 \\ ajiao20081204@126.com, b42446028@qq.com, '519044134@qq.com \\ ${ }^{*}$ Corresponding author
}

Keywords: Product Design, Aesthetics, Ergonomics, Evaluation Standard, Evaluation Method

\begin{abstract}
The evaluation standard of product design is different for people, region, environment, which affected by many factors, especially the coordination between aesthetics and Ergonomics. Only by coordinating their relationship rationally can highlight its advantage in market competition. This article mainly discusses how to coordinate the relation ship between aesthetics and ergonomics in product design, particularly the coordination process in which the process and basic elements of product design based on the case of "Modeling Design in Self-express Service System Based on the University City". Finally we try to put forward an evaluation standard of product quality and a method of coordinating aesthetics and Ergonomics. Although this is just a tentative research, it will make a great role in promoting product design in the future.
\end{abstract}

\section{Introduction}

Nowadays, people's demands for product have been changed. Consumers' demands for product have changed from pursuit of humanization to satisfaction of usability and aesthetics.

How to coordinate the relationship between aesthetics and ergonomics in product design? In terms of different types of products, the focal point of research is different. Household products pay attention to practical function and consumers always choose things which is safe, convenient and comfortable; In order to satisfy different customer's demands, car design not only focus on safety and comfort but also the sense of modeling beauty.

\section{Aesthetics and Ergonomics in product design}

\section{Product design process}

The concept of "design" has appeared in ancient times. But "design" in this paper derived from English word, which means invention and creation. Product design covers the whole process of idea propose, generation, formation, product molding and finally putting into use (refer with: Fig. 1). The core of product design is functional structure. The coordination of form, material and color can increase the product popularity. Therefore, rationally coordinate their relationship can design a perfect product. 


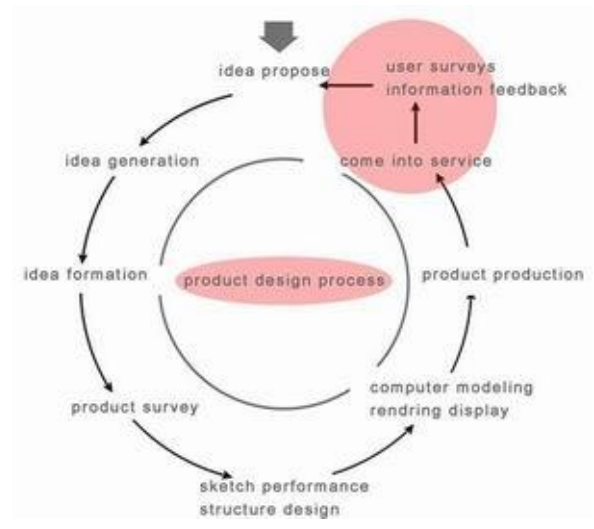

Figure 1 Product design process

\section{Demands of product design}

Consumers' understanding of product starts with vision, audition and any other sense. And then they know more about the function and connotation through the use. Therefore, users' demands for product not only include function but also other four aspects as following: functional requirements, usability requirements, ergonomics requirements, aesthetics requirements and symbolic requirements.

\section{Functional requirements}

Functionality is aim at the use of consumers. They purchase the product mainly for its functions. Functional requirements are the core demand of products [1]. Generally speaking, functional requirements go throughout the whole design process. Consumers understand the product features by using and finally decide whether to buy it.

\section{Usability requirements}

Usability is taken into consideration after functionality is satisfied. It requires product convenient and quick to use. Different line, shape, color, size etc respectively represent different implications and consumer can judge its semantics according to the comparison.
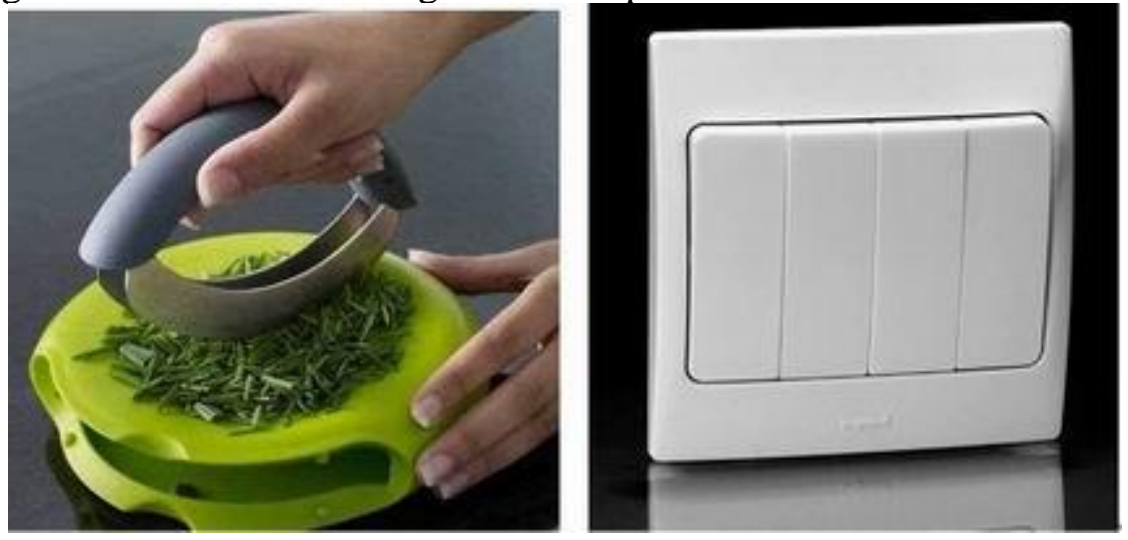

Figure 2 Comparison of good and bad product semantics

Pay attention to the comparison of good and poor product semantics as shown in Figure 2. The former handle use the curve to make users judge the handheld part; the latter switch may let the users confused that which orientation corresponds to on or off. Thus it can be seen that reasonable product form can satisfy consumer's demands for usability.

Ergonomics requirements

The main purpose of ergonomics is to ensure safety and comfort. In general, improve product operation efficiency [2]. User is the main point of product design. The mixture of ergonomics makes 
product much more human. New product should conform to the original functionality and meet people's special requirements.

\section{Aesthetics requirements}

Users focus much more on technology, shape, style, color etc.In the case of same quality, users tend to select products which are elegant in appearance, and harmonious in color.

Beauty of product includes external and internal beauty. External beauty mainly embodied through the form. It can not only transmit the meaning of aesthetics, spirit and culture etc, but assist in carrying out products' functions as well[3].

\section{Symbolic requirements}

Users infuse product with certain social significance, which makes the users get certain psychological satisfactions and embody their identity and status in society by some specific products [4]. Therefore, symbolic requirements are consumers' assessment of total quality and self-fulfilling process, which can reflect consumer's values at the same time.

\section{Relationship between aesthetics and Ergonomics in product design}

Ergonomics in product design involves all kinds of static and dynamic sizes of body and situation adapted to the environment. Aesthetics add emotion factors to products in order to attract consumers' attention. Ergonomics and aesthetics are both related and conflicted with each other in product design.

1. Relevancy between ergonomics and aesthetics. They affect each other, so designers need to consider them according to practical circumstances. For instance, tools design puts more emphasize on function and safety. But as a commodity, it needs to achieve its sales goal through aesthetics.

2. Conflict between Ergonomics and aesthetics. Products can not satisfy all the requirements of ergonomics and aesthetics. The most obvious example is machinery product which has single shape and great function. Designer should take ergonomics into consideration firstly and then aesthetics.

\section{Aesthetics and Ergonomics in Self-express Service System}

Express refers to the logistics activity with the post function. In this paper, the students of Jiangsu University are choosed to be the studying objects. We integrate 'self-service' into express and design a new type of express service system. It is more convenient and can reduce the manpower and material.

\section{Design and analysis of Packaging Box Self-service sales system}

The basic function of this system is to store and sale the package boxes. Consequently, the coin slot, banknotes slot, small screen etc. should be set in appropriate place based on functional requirement, using process and ergonomic requirements (refer with: Fig. 3).

Screen altitude usually depends on the average value of 5th percentile of male and female eye height. In addition, it is the most appropriate distance when screen is $300 \mathrm{~mm}$ away from the user and the angle between screen and vertical direction is 30 degree. The screen height is set about $1400 \mathrm{~mm}$ based on the Posture Human Dimensions of Chinese Adults GB/T10000-1988[5]. To meet most users' habit, the slot and change services is on the bottom of the screen. The height of doorknob is about $1200 \mathrm{~mm}$ on the basis of functional height.

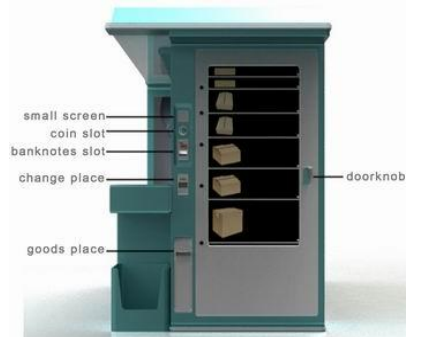

Figure 3 Design of self-service sales system

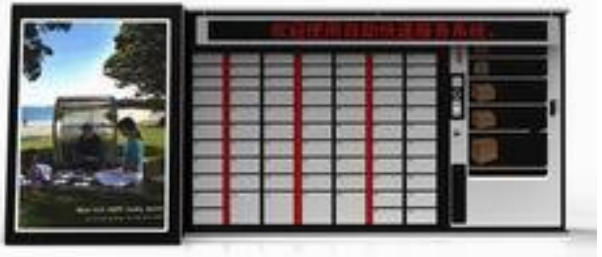

Figure 4 Total design of self-service express service system 
Based on the satisfaction of the functions above, we neatly organize package box on the main display area of the sales system. It highlights the main function and gives users the impression of clarity, brevity, coordinating and unifying.

\section{Package storage area design}

The main function of this area is storing all kinds of package. We get following data according to the survey of express filiales in Jiangsu University (refer with: Table 1).

Table 1 Statistical table of campus express survey data

\begin{tabular}{|l|l|l|l|}
\hline Express name & $\begin{array}{l}\text { Receive number } \\
{[\text { Pieces / day }]}\end{array}$ & $\begin{array}{l}\text { Send number } \\
\text { [Pieces / day }]\end{array}$ & Remark \\
\hline YunDa Express & $200 \sim 300$ & $20 \sim 30$ & \\
\hline STO Express & $500 \sim 600$ & About 200 & \\
\hline YT Express & $300 \sim 400$ & $30 \sim 40$ & $\begin{array}{l}80 \%(240 \sim 320 \text { pieces }) \text { is small; } \\
\text { 20\%(60 80 pieces) is large; } \\
\text { Individual pieces are urltra large. }\end{array}$ \\
\hline
\end{tabular}

According to the distribution of seven dormitory areas in Jiangsu University, we assume that 480 deposit boxes are set and accommodate 140 packages. Under the condition of allowance, 70 deposit boxes are set in each dormitory area, which can contain 20 packages (refer with: Fig. 4).

Table 2 Data table of deposit boxes

\begin{tabular}{|c|c|c|c|c|c|c|}
\hline Name & $\begin{array}{c}\text { Original } \\
\text { Size }[\mathrm{mm}]\end{array}$ & $\begin{array}{l}\text { Survey } \\
\text { number }\end{array}$ & $\begin{array}{c}\text { Size } \\
{[\mathrm{mm}]}\end{array}$ & $\begin{array}{c}\text { Total } \\
\text { number }\end{array}$ & $\begin{array}{l}\text { Subarea } \\
\text { number }\end{array}$ & Remark \\
\hline Express bag & $40 * 30 * 9$ & $50 \sim 70$ & $35 * 15$ & 120 & 20 & \multirow{5}{*}{$\begin{array}{l}\text { The depth of the deposit box } \\
\text { is } 400 \mathrm{~mm} \text {; } \\
\text { x represent thickness of file } \\
\text { pocket; } \\
\text { y represent thickness of letter. }\end{array}$} \\
\hline Middle box & $23 * 12 * 14$ & $70 \sim 100$ & $15 * 15$ & 120 & 20 & \\
\hline Small box & $12 * 10 * 8$ & $30 \sim 40$ & $15 * 15$ & 72 & 12 & \\
\hline File pocket & $20 * 18 * x$ & $>10$ & $20 * 4$ & 24 & 4 & \\
\hline Letters & $23 * 33 * y$ & $>10$ & $25 * 4$ & 24 & 4 & \\
\hline
\end{tabular}

According to the survey of Jiangsu University campus express filiales, we got exactly size and magnitude relation of package (refer with: Table 2).

According to the survey data and allowance need, set the depth of the deposit box as $400 \mathrm{~mm}$. Take the rational use of space into account, at last confirm three size types (refer with: Table 3 ).

Table 3 Table of deposit box size

\begin{tabular}{|c|c|c|c|}
\hline Type & Size $[\mathrm{mm}]$ & Number & Remark \\
\hline Small type & $10 * 30$ & 21 & \multirow{3}{*}{$\begin{array}{l}\text { The depth of } \\
\text { deposit box is } \\
400 \mathrm{~mm} \text {. }\end{array}$} \\
\hline middle-large type & $15 * 30$ & 48 & \\
\hline super-huge type & $30 * 32$ & 4 & \\
\hline
\end{tabular}

The design of this area includes the deposit box size, so it should be calculated based on the survey data strictly. In addition, the utilization rate of space should be taken into consideration.

\section{Self-service post system design}

In accordance with post process (refer with: Fig. 5), the delivery area is divided into operating screen, payment area, storage table, weighting table and package entry etc (refer with: Fig. 6).

1. The height of operating screen and self-service sales area is $1400 \mathrm{~mm}$.

2. Payment function area also has coin slot, banknotes slot, change-slot on its right side; the roll of receipt paper is perched under the screen to meet the functional height of human's arm.

3. To apply to most users, the height of weighting table is set to $1000 \mathrm{~mm}$ according to the 5th percentile eye height of male and female [5].

4. According to the height of human elbow we set the height of weighting table and package entry to $800 \mathrm{~mm}$. And the height of small package entry is set to $1600 \mathrm{~mm}$ based on the average data of humans' arm [5]. In order to satisfy all size of package, the delivery opening is set to $400 * 300 \mathrm{~mm}$ 
and the depth is $400 \mathrm{~mm}$. If put 10 packages in it at the same time, the entry height is $800 \mathrm{~mm}$. Therefore the width of using space should be higher than $1500 \mathrm{~mm}$. Take allowance requirements and error into consideration, finally the width of using space is set to $1600 \mathrm{~mm}$.

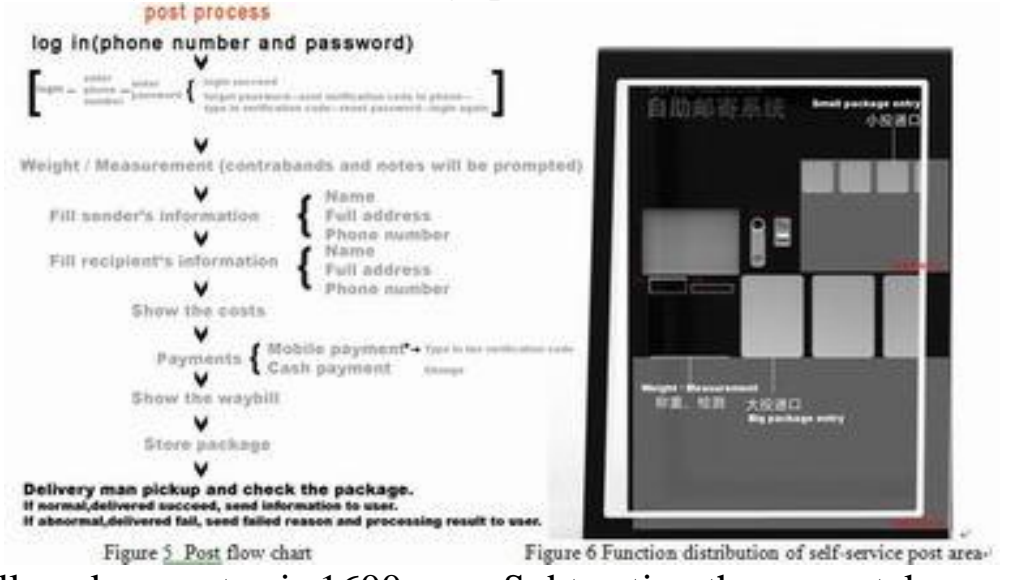

The height of small package entry is $1600 \mathrm{~mm}$. Subtracting the space taken on big package, the remaining use space is $400 * 800 * 400 \mathrm{~mm}^{3}$. If the size of small package is $150 * 150 \mathrm{~mm}$, it can hold ten packages. From this knowable, post space can contain twenty packages. The quantitative analysis is main way in this design process, in which the aesthetics is hardly involved for the design orientation. As service products, functionality and usability is the main point and aesthetics only should be taken into consideration as added value.

\section{Overall form design and analysis}

Express industry in our country is the inheritance and development of post house. It brings convenient and efficient service for human. Based on this, we propose some key words in modeling design. Finally, we choose traditional and post house, modern and sense of speed to design.

1. Tradition and post house. Post house and express have similar function and process. So we integrate characteristic elements of post house into this modeling design and form specific semantic orientation. Convex advertising board breaks the monotony of repetition. This structure can also direct rainwater to run down along the both sides. On the color design, we choose ZJS express as the virtual customer. We integrate white, dark grey into blue-green to show the feeling of elegance and calmness. We hope it can give users the impression of quiet and comfort (refer with: Fig. 8) [6].
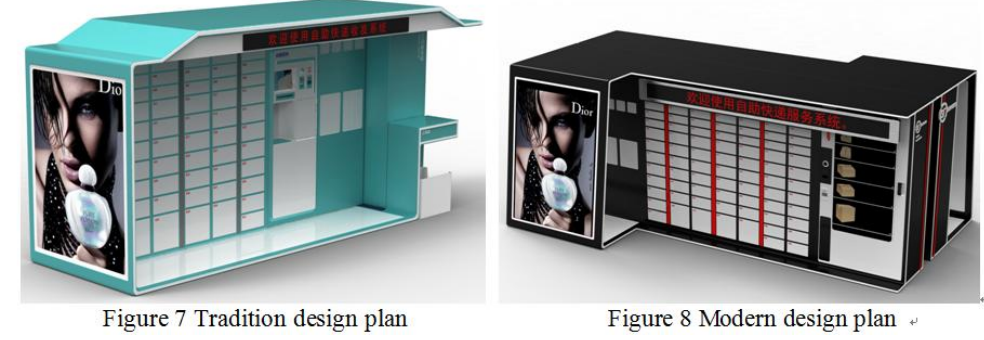

2. Modern and sense of speed. People increasingly go after speed. This modeling design is simple, which can meet the function requirements. Convex hood of post area plays a protective role and breaks the monotone. On the color design, this case refers to the collocation of SF express. The main color of this concept is black and white and red are used as ornament. The whole modeling design is tranquil and vivacious, which can give users the impression of rational, modern and safe.

\section{Coordination between Ergonomics and aesthetics in self-service express service system}

In this paper, Jiangsu University is chosen as use environment. We need to deeply analyze the relationship between consumer and product from the students' perspective. And form complete system of human, machine and environment. Consumers obtain correct indication and physiological feedback in proper modeling semantic and color matching. Sequentially they rapidly and accurately judge product category, using function etc. So when aesthetics conflicts with ergonomics, the latter 
should be given priority. In this case ergonomics is much stronger than aesthetics, which may limit the express of aesthetics. In contrast, aesthetics can promote interaction.

\section{Proposal of Ergonomics and aesthetics coordinate approach and evaluation standard}

\section{Ergonomics and aesthetics coordinate approach}

Based on the analysis above, we put forward product evaluate standard and method in this paper. It is mainly divided into the following three steps.

1. Importance analysis of product design requirements. This is a very important step at the beginning of product design. Designer must ensure the purpose of design, intensity of needs and clearly defined goal (refer with: Table 4).

Table 4 Importance analysis of product design requirements

\begin{tabular}{|l|l|l|l|l|l|}
\hline $\begin{array}{l}\text { Requirements } \\
\text { need to satisfied }\end{array}$ & $\begin{array}{l}\text { Functional } \\
\text { requirements }\end{array}$ & $\begin{array}{l}\text { Usability } \\
\text { requirements }\end{array}$ & $\begin{array}{l}\text { Ergonomics } \\
\text { requirements }\end{array}$ & $\begin{array}{l}\text { Aesthetics } \\
\text { requirements }\end{array}$ & $\begin{array}{l}\text { Symbolic } \\
\text { requirements }\end{array}$ \\
\hline Intensity & $\begin{array}{l}90 \%, \text { very } \\
\text { strong }\end{array}$ & $70 \%$, strong & $\begin{array}{l}90 \%, \text { very } \\
\text { strong }\end{array}$ & $\begin{array}{l}60 \%, \\
\text { ordinary }\end{array}$ & $30 \%$, weak \\
\hline
\end{tabular}

2. Importance judge of ergonomics and aesthetics. Through analysis we can divide it into two categories. Formal beauty and symbolic requirements belong to aesthetics; other three kinds belong to ergonomics. Then we can define regulation and judge the importance by quantitative analysis.

3. Coordination of aesthetics and ergonomics. If aesthetics conflicts with ergonomics, designer can judge how to choose through importance analysis and minimize the loss.

\section{Evaluation standard of product}

This article put forward a hypothesis of product evaluation standard. Through the analysis of related factors evaluate product grade (refer with: Table 5).

Table 5 Evaluation standard of product

\begin{tabular}{|l|l|l|l|}
\hline \multicolumn{1}{|c|}{$\begin{array}{c}\text { Influence } \\
\text { elements }\end{array}$} & \multicolumn{1}{|c|}{ Excellent } & \multicolumn{1}{|c|}{ Fine } & \multicolumn{1}{c|}{ Bad } \\
\hline $\begin{array}{l}\text { Functional } \\
\text { requirements }\end{array}$ & $\begin{array}{l}\text { Satisfy basic and additional functional } \\
\text { requirements. }\end{array}$ & $\begin{array}{l}\text { Satisfy basic functional } \\
\text { requirements. }\end{array}$ & $\begin{array}{l}\text { Does not satisfy basic } \\
\text { functional requirements. }\end{array}$ \\
\hline $\begin{array}{l}\text { Usability } \\
\text { requirements }\end{array}$ & $\begin{array}{l}\text { Convenient and requires less time for } \\
\text { consumer to use, it also accord with } \\
\text { their behavior. }\end{array}$ & $\begin{array}{l}\text { Convenient but need more } \\
\text { time to read the instructions } \\
\text { and learn how to use. }\end{array}$ & $\begin{array}{l}\text { It is difficult to use or need } \\
\text { special training to learn. }\end{array}$ \\
\hline $\begin{array}{l}\text { Ergonomics } \\
\text { requirements }\end{array}$ & $\begin{array}{l}\text { Its size meets the Ergonomics } \\
\text { requirements, humanize, comfortable } \\
\text { and safe. }\end{array}$ & $\begin{array}{l}\text { Its size meets the basic } \\
\text { Ergonomics requirements. }\end{array}$ & $\begin{array}{l}\text { Does not meet Ergonomics } \\
\text { requirements. }\end{array}$ \\
\hline $\begin{array}{l}\text { Aesthetics } \\
\text { requirements }\end{array}$ & $\begin{array}{l}\text { Accord with the contemporary } \\
\text { aesthetics, combined with function } \\
\text { appropriately, consumer can feel the } \\
\text { connotation of culture, era, etc. }\end{array}$ & $\begin{array}{l}\text { Accord with contemporary } \\
\text { aesthetics; integrate into } \\
\text { culture, era, etc. }\end{array}$ & $\begin{array}{l}\text { Basic function and crude } \\
\text { form. }\end{array}$ \\
\hline $\begin{array}{l}\text { Symbolic } \\
\text { requirements }\end{array}$ & $\begin{array}{l}\text { Formed brand culture, reflect social } \\
\text { status, taste etc. } \\
\text { Elegant don't lose poise. }\end{array}$ & $\begin{array}{l}\text { Reflect particular social } \\
\text { status, taste and social } \\
\text { symbolic significance etc. }\end{array}$ & $\begin{array}{l}\text { Don't reflect any social } \\
\text { symbolic significance. }\end{array}$ \\
\hline
\end{tabular}

This evaluation standard takes five product design requirements as goal. Different evaluation standard will be set according to the final goals that we need to achieve. Evaluation processes correspond to their respective evaluation standard for different needs of products. Designer can randomly make investigation on product consumers and let them evaluate based on the table above.

\section{Conclusion}

With the development of living standard, self-service is gradually popular. Self-service express service system arises at this historic moment. It gives a thorough analysis of product relationship. We try to combine practicability and beauty properly [7]. Anything in our life need to design and it always involves in coordination problem about ergonomics and aesthetics. Car design is a classic case. Firstly, it should satisfy fundamental function of 'transport'; secondly, it needs to follow the ergonomics standard to ensure safety and conformable use; lastly, we should do survey about users' aesthetics view and requirements to seize market shares. 
In conclusion, only following the product design purpose and understanding the main idea of design and relationship between ergonomics and aesthetics can we design a good product. As the development of self-express service is not mature and the information available in this article is limited, final result is not perfect. Finally it needs our further study to improve and examination.

\section{Acknowledgments}

This work was financially supported by "the Fundamental Research Funds for the Central Universities"(2013B34214).

\section{References}

[1]. Zhao Decheng, Product modeling design, Ocean Press (In Chinese), Beijing, 2010.

[2]. Li Zhe, Sun Lan, Zhang Fuchang, Ergonomics in Kitchen Small Tool Design Application, Journal of Hefei College. Vol. 17, No. 1, 2007.

[3]. Shang Miao, Product form design, Wuhan University Press, Hubei, 2010.

[4]. Wang Huiqin, Consumption psychology, Southeast university press, Nanjing, 2005.

[5]. Ding Yulan, Ergonomics, Beijing Institute of Technology Press, Beijing, 1991.

[6]. Yuan Enpei, Jia Rongjian, Color design, China Machine Press, Beijing, 2010.

[7]. Zhang Shengru, Primary investigation of self-help service economy in E era, Scientific and Technical Information (Science Research). No. 1, 2008. 